\title{
NARRATIVAS DE VIDA: UM INSTRUMENTO SEMIÓTICO FAVORÁVEL AO TRABALHO DE ORIENTAÇÃO EDUCACIONAL NO ENSINO BÁSICO
}

\author{
NARRATIVAS DE VIDA: UN INSTRUMENTO SEMIÓTICO FAVORABLE AL TRABAJO DE \\ ORIENTACIÓN EDUCATIVA EN EDUCACIÓN BÁSICA
}

https://orcid.org/0000-0003-3313-9925 Júnia Garcia França Mota ${ }^{\text {A }}$
https://orcid.org/0000-0003-1570-1996 Ana Paula de Freitas ${ }^{\text {B }}$
${ }^{\text {A } \text { Universidade São Francisco (UFS),Itatiba, SP, Brasil }}$
${ }^{\text {B Universidade São Francisco (UFS),Itatiba, SP, Brasil }}$
Recebido em: 30 set. 2020 | Aceito em: 31 mar. 2021
Correspondência: Júnia Garcia França Mota (jgfrancamota@gmail.com)

\section{Resumo}

As projeções e legitimidade do uso de narrativas na educação vêm conquistando importante espaço no contexto escolar em razão de seus valores enquanto produção discursiva, metodologia de pesquisa e formação. Sustentada nos ideais teórico-metodológicos da teoria histórico-cultural e compreendendo a narrativa como atividade simbólica mediadora de processos de elaboração de conhecimento, esta produção visa partilhar uma experiência idealizada, desenvolvida e relatada por uma orientadora educacional acerca de produção de narrativas escritas por alunos do Ensino Fundamental. Apresenta-se, neste texto, relatos orais da orientadora sobre suas motivações para realizar a atividade e sua apreciação a respeito dela. A intervenção com narrativas foi considerada um instrumento acessível e favorável ao atendimento das intenções da especialista, contribuindo para o entendimento das singularidades e modos de vida dos alunos.

Palavras-chave: Perspectiva histórico-cultural; Narrativa; Instrumento técnico- semiótico; Educação Básica.

\section{Resumen}

Las proyecciones y legitimidad del uso de las narrativas en la educación han ido ganando un espacio importante en el contexto escolar por sus valores como producción discursiva, metodología de investigación y formación. Partiendo de los ideales teórico-metodológicos de la teoría histórico-cultural y entendiendo la narrativa como una actividad simbólica que media en los procesos de desarrollo del conocimiento, esta producción tiene como objetivo compartir una experiencia idealizada, desarrollada e informada por un asesor educativo sobre la producción de narrativas escritas por estudiantes de enseñanza fundamental. En este texto se presentan informes orales de la asesora sobre sus motivaciones para realizar la actividad y su agradecimiento por la misma. La intervención con narrativas se consideró un instrumento accesible y propicio para atender las intenciones del especialista, contribuyendo a la comprensión de las singularidades y formas de vida de los estudiantes.

Palabras clave: Perspectiva histórico-cultural; Narrativa; Instrumento técnico-semiótico; Educación Básica. 


\section{Introdução}

A produção deste relato de experiência estruturou-se nos ideais teóricos e metodológicos da perspectiva histórico-cultural, especialmente nas proposições de Lev Seminovich Vygotsky acerca da natureza social da constituição e desenvolvimento humano.

Nessa direção, faz-se pertinente destacar a consonância das proposições de Vygotsky ${ }^{i}$ pautados no materialismo histórico que envolvem o sujeito em sua existência. Sujeito esse materialista e histórico, que se constitui, aprende e se desenvolve em meio a contradições, coisas, relações, contextos e processos que o atravessam.

[...] Vigotski concluiu que as origens das formas superiores de comportamento consciente deveriam ser achadas nas relações sociais que o indivíduo mantém com o mundo exterior. Mas o homem não é apenas um produto de seu ambiente, é também um agente ativo no processo de criação deste meio. (LURIA, 2018, p. 25)

Segundo Vygotsky (1991, p. 17), a perspectiva histórico-cultural se orienta por "caracterizar os aspectos tipicamente humanos do comportamento e elaborar hipóteses de como essas características se formaram ao longo da história humana e de como se desenvolvem durante a vida de um indivíduo." Seus ideais vislumbram explicar a natureza de processos tipicamente humanos que emergem das relações vivenciadas pelos sujeitos nas práticas sociais aspecto essencial à compreensão do funcionamento psíquico do ser humano.

Neste sentido, Martins (2020) reflete sobre as proposições do autor:

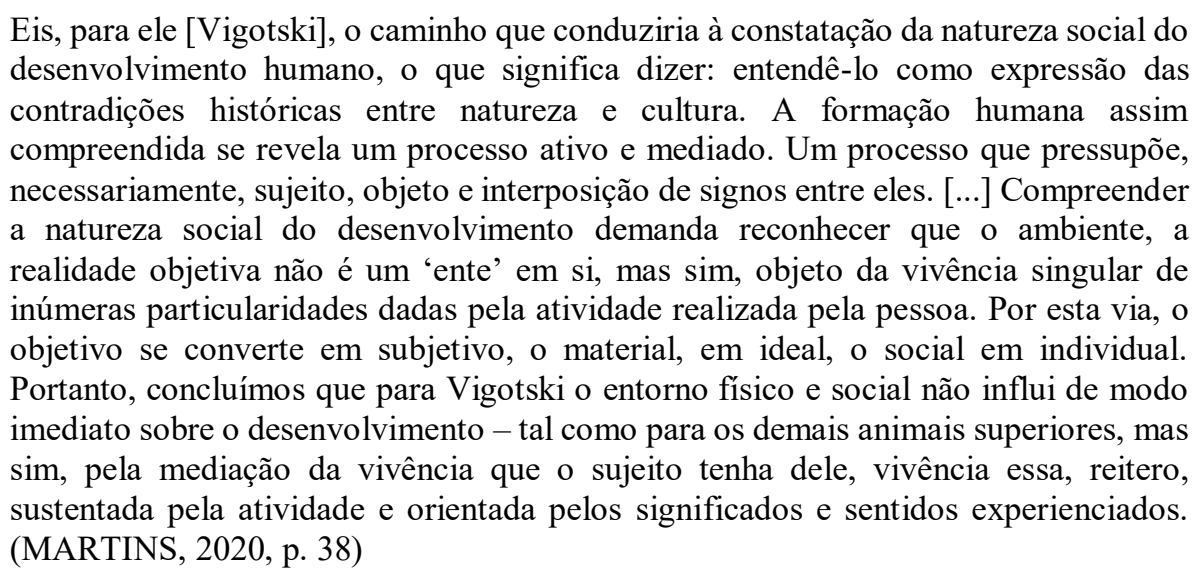

Para Martins (2013), a educação escolar tem papel preponderante no desenvolvimento do psiquismo humano, pois é via de acesso ao conhecimento elaborado na/pela cultura humana. Tendo em vista o contexto desafiador da educação básica, sobretudo, pela diversidade de alunos que habitam a escola, em condições sociais, econômicas e culturais desiguais, a autora compreende "a educação escolar como processo privilegiado para, no âmbito da transmissão dos conhecimentos, opor-se às referidas desigualdades" (MARTINS, 2013, p. 272). 
Santos e Sant'ana (2016) destacam em seus estudos que as características psicológicas e comportamentais do homem são passíveis de transformação, mediante o contexto sóciohistórico que o perpassa e a partir do qual ele emerge. Nessa direção, olhar as questões escolares a partir da perspectiva histórico-cultural é uma possibilidade para as instituições vislumbrarem as singularidades de seus alunos a partir da observação e compreensão de seu modo de vida, contextos e relações que os perpassam.

Com base nisso, compreende-se que as relações intersubjetivas vividas pelos alunos nas práticas sociais escolares impactam sua constituição de maneira singular. A depender do modo como essas práticas são oferecidas, das mediações possíveis neste contexto, os alunos poderão ter acesso ao conhecimento elaborado na/pela cultura humana (DAINEZ; SMOLKA, 2019). Tais ideias mobilizaram uma especialista em orientação educacional a desenvolver um trabalho com alunos do segundo ciclo do ensino fundamental, a fim de compreender as suas demandas escolares.

A produção de narrativas escritas foi tomada como instrumento técnico-semiótico que elucidou o entendimento acerca da realidade, das necessidades e da singularidade desses alunos.

Sirgado (2000), orientado pelos pressupostos vygotskyanos acerca da mediação semiótica, explica que como técnica, a mediação permite ao homem dar uma nova forma à natureza e, como semiótica, a essa forma nova é dada uma significação.

Nessa direção, Freitas (2019, p. 49) compreende a narrativa como um instrumento técnico-semiótico, na medida em que "narrar é uma atividade de linguagem sígnica, que incide sobre o sujeito que narra e regula seu pensamento". Para a autora, a narrativa como instrumento técnico-semiótico possibilita ao narrador refletir sobre suas experiências e, a partir disso, transformar-se. Ao mesmo tempo, como narrar implica um interlocutor, a narrativa pode afetar e mobilizar transformações no outro. A hipótese é que as narrativas, como instrumento técnicosemiótico, potencializam a melhoria, tanto da qualidade do ensino como das relações entre escola-aluno-família.

Com a intenção de relatar e refletir sobre o trabalho desenvolvido pela orientadora educacional, este texto organiza-se em três seções.

Na primeira seção, evidencia-se fundamentos dos estudos narrativos que estruturam as reflexões aqui pretendidas. Em seguida, na seção 'Uma experiência escolar utilizando narrativas escritas por alunos' contextualiza-se a função da orientação educacional e explicitase a ação desenvolvida e as reflexões realizadas. A última seção traz algumas considerações sobre a experiência relatada neste artigo. 


\section{As narrativas e o seu valor no contexto da educação escolar}

Nesta produção destaca-se os valores acerca do uso de narrativas como forma de expressão e de produção discursiva, tendo em vista as singularidades, as condições de experiências, os sentimentos, os modos de vida e os sentidos produzidos pelos sujeitos que narram, a partir de sua experiência de vida em dado contexto histórico-cultural.

Nessa direção, Hanke (2003) destaca, em sua abordagem, a narrativa como um meio de percepção, sendo a realidade um produto de uma construção narrativa que parte da estruturação das experiências vividas pelo ser humano.

A partir das narrativas são construídas teorias sobre a realidade (Ochs et al. 1992), e, sendo assim, elas servem como "ponto de fuga através do qual torna-se possível a apreensão do cotidiano" (Mendonça et al. 2001, p. 9). Elas são meios de sociabilidade, pois através delas as experiências individuais são comunicadas e tornadas "públicas" ou socialmente conhecidas. (HANKE, 2003, p. 118)

Para Bruner (2002) a narrativa pode ser caracterizada como uma forma discursiva “inerente à práxis da interação social”. (BRUNER, 2002, p. 72). Ademais, é por meio das narrativas que o ser humano tende a organizar sua experiência social e "no exercício da narrativa, negocia significados em uma prática partilhada socialmente, permitindo a construção de novas redes de significações sobre a realidade.” (GONÇALVES et al., 2016, p. 109). Logo, a partir do discurso narrativo, é possível o acesso e a interpretação de dados da cultura de um sujeito, com vistas a mediar sua própria experiência e representar a sua realidade. (GONÇALVES et al., 2016, p. 108)

As narrativas se organizam socialmente a partir das diversas formas de linguagem: a falada, a escrita e a artística, carregando, em si, segundo Aguiar e Ozella (2006), relações de historicidade, de ideologia e de representações sociais.

Nessa direção e a despeito das questões de linguagem no contexto da comunicação educacional e nas mudanças sociais, Mascia e Kontopodis (2010) trazem sua colaboração empenhando-se em uma análise sobre uma produção pictórica. Nesse contexto mencionado, os autores argumentam, a partir de um diálogo entre Foucault e Vigotski, como esse tipo de produção artística, bem como outras formas de contextos narrativos, pode ser relevante enquanto instrumentos semióticos a serem usados no contexto escolar como forma de mediação de discursos entre professores e alunos. Ao analisar a produção da pintura, observam que a obra analisada

tem o efeito de mediar a comunicação entre o pintor e o público e, ao mesmo tempo, de mediar o discurso interior do pintor e o do espectador. O quadro possibilita uma reflexão acerca dos sujeitos, do tema ou do objeto representados de várias maneiras (Fichtner, 2005). O mesmo pode-se dizer com relação a ferramentas semióticas ou meios de comunicação, incluindo as narrativas, os filmes e os artefatos 5 . Tais meios 
são frequentemente usados em contextos escolares [...] Os/as estudiosos/as, ao usar abordagens socioculturais e histórico-culturais de ensino, de aprendizagem e de desenvolvimento, têm estudado amplamente como as ferramentas semióticas (tais como uma narrativa ou uma pintura) simultaneamente medeiam a comunicação entre professores/as e alunos/as, adultos e crianças, e o "discurso interior" de um sujeito para si próprio, bem como moldam o pensamento e a imaginação [..]. (MASCIA; KONTOPODIS, 2010, p. 453)

Segundo Hanke (2003), a narrativa pode ser considerada como uma atividade linguística, uma forma básica de comunicação cotidiana e uma importante habilidade inerente ao ser humano. "Como produto arcaico da cultura humana, as narrativas servem, dentre outras funções básicas, para acumulação, armazenamento e transmissão de conhecimentos" (HANKE, 2003, p. 118), sendo, dessa forma, de grande relevância nos estudos que se referem aos conhecimentos na área da educação escolar.

Na perspectiva de Teixeira (2010), a narrativa não possui seus valores somente no campo linguístico:

[...] parece certo que, só recentemente, o termo narrativa não nos transporta apenas para o mundo da literatura e da criação literária. Atualmente é já um dado adquirido que a narrativa se constitui como uma metáfora e o instrumento de um novo paradigma de entendimento, de observação e de compreensão psicológica e educativa. (TEIXEIRA, 2010, p. 124)

As pesquisas de Frauendorf et al. (2016) também destacam a relevância das narrativas na área da educação. Segundo o autor, pesquisas nesta área utilizam-se da análise (da) narrativa como fonte de dados e/ou como forma de produção de dados para a pesquisa qualitativa, contribuindo, satisfatoriamente, para a "compreensão do cotidiano escolar, das práticas docentes e das relações que ocorrem e emergem dessas instituições." (FRAUENDORF et al., 2016, p. 353)

$\mathrm{Na}$ direção de também ressaltar o papel da narrativa de alunos como um importante instrumento de intervenção no contexto escolar, Passeggi (2018) propõem que o uso das narrativas de sujeitos envolvidos na educação escolar é um aspecto de grande valor neste âmbito, pois:

[...] vozes de professores [...] vozes de jovens e de crianças, cada qual com seus dizeres e fazeres, seus modos humanos de ser, de sentir, de viver, de interagir e de constituir como agente ao longo da vida. Modos de continuar resistindo às lógicas que se interpõem a um mundo melhor, existindo e insistindo para fazer com essas lógicas, outros modos de viver num mundo melhor. (PASSEGGI, 2018, p. 14)

Na ótica de Passeggi (2010), a exploração de contextos utilizando-se das narrativas, é guiada pelo desejo de considerar o que o sujeito pensa sobre si, sobre o mundo, e como dá sentido às suas ações e toma consciência de sua historicidade. Neste âmbito, é possível, segundo a autora, investigar o "processo de construção do sujeito na interação dialética entre espaço 
social e o espaço pessoal" e analisar os modos como os sujeitos dão forma e sentido às experiências vividas na interação com os outros e no percurso de sua formação enquanto criatura humana (PASSEGGI, 2010, p. 111). Para a pesquisadora, três princípios guiam as investigações biográficas: a construção da realidade pelo sujeito, o papel da linguagem como mediadora da construção dessa realidade e o sujeito, que ao narrar, transforma sua vida em texto narrativo, em um trabalho interpretativo. Ao refletir sobre a problemática que mobiliza a pesquisa biográfica, a autora enaltece a figura central da pessoa e sua capacidade de elaboração sobre si:

\footnotetext{
No centro de suas inquietações coloca-se a pessoa humana, acreditando-se nela e em sua capacidade de reflexão sobre si mesma. Não se busca obstinadamente a "verdade objetiva", pois se tem a consciência de que a "realidade" passa, obrigatoriamente, pela mediação dos sistemas simbólicos, constitutivos do imaginário social, que é, por sua vez, subjetivado pelos indivíduos. (PASSEGGI, 2010, p. 112)
}

Dessa forma, por meio da investigação narrativa, da escrita de vida, é possível explicar aspectos nas interações ocorridas em sala de aula, sendo necessário, para tanto, que se produza um discreto giro na mente do pesquisador, no intuito de que seja possível ver e descrever relatos de ações diárias dos mesmos (CONNELLY; CLANDININ, 1995) e, a partir daí, traçar o caminho no sentido de trabalhar no desenvolvimento do processo de ensino e de aprendizagem a partir da coletividade.

Nessa direção, é possível propor ainda, que assumir uma investigação pautada na metodologia narrativa, significa assumir uma concepção epistemológica diferenciada, atualizada e coerente com as necessidades humanas e contemporâneas da educação escolar (CONNELLY; CLADININ, 1995; FRAUENDORF et al. 2016), encerrada na análise e na interpretação de dados, nas experiências vividas pelos alunos levando em consideração a subjetividade e a singularidade deles.

Frente aos argumentos teóricos mencionados acerca dos valores das narrativas de vida, o objetivo deste relato é partilhar uma experiência vivida por uma especialista em orientação educacional que utilizou de narrativas escritas por alunos de uma escola de educação básica regular de ensino público do estado de Minas Gerais, com vistas a conhecer seus modos de vida e, a partir disso, pensar ações educacionais favoráveis ao processo de ensino e de aprendizagem desses alunos.

\section{Uma experiência escolar utilizando narrativas escritas por alunos}

A fim de relatar a experiência vivida pela orientadora educacional, julga-se necessário, inicialmente, explicitar a sua função. 
Trata-se de uma função pedagógica cuja formação se dá no contexto de cursos de Pedagogia, em disciplinas voltadas à gestão educacional da educação básica. Corroborando com essa perspectiva e com a caracterização do gestor educacional, Pascoal, Honorato e Albuquerque (2008, p. 102) observam que, "historicamente, os cursos de Pedagogia têm formado profissionais para o exercício de funções ligadas à gestão educacional" entre os quais, além dos administradores escolares e supervisores de ensino, estão os orientadores educacionais.

Cabe ao orientador educacional a função de mediação das relações que envolvem o contexto sócio-histórico que perpassa o fazer escolar. Nessa direção, Pascoal, Honorato e Albuquerque (2008) destacam que a orientação educacional é uma função partícipe da gestão educacional de grande relevância, podendo se desenvolver no contexto escolar a partir de cinco áreas de sua atuação: o aluno, a escola, a família, a comunidade e a sociedade.

[...] Em outras palavras, o papel do orientador educacional deve ser o de mediador entre o aluno, as situações de caráter didático-pedagógico e as situações socioculturais. Além disso, a razão de ser da escola e da própria educação é o aluno, centro dos estudos da orientação educacional. (PASCOAL; HONORATO; ALBUQUERQUE, 2008, p. 103)

Contudo, ressaltam que "a existência e a permanência do orientador educacional na rede escolar são bastante questionadas e o enfoque dado às atividades que desempenha passa por modificações, de acordo com os estados, em suas regulamentações" (PASCOAL; HONORATO; ALBUQUERQUE, 2008, p. 102).

Para os autores, a respeito da função do orientador educacional no contexto das escolas brasileiras, é comum encontrar escolas que não contam com a assistência deste gestor em seu quadro de profissionais da educação. Eles afirmam que, em muitos estados brasileiros, a trajetória do orientador educacional foi marcada por diferentes situações: os avanços, as contradições, os recuos e até mesmo a sua extinção e a consequente perda de seu espaço funcional.

Pascoal (2006) ressalta que ao mudar de Estado, é comum o orientador educacional se deparar com realidades bastante distintas em sua função educacional. Função esta por vezes restrita ou até inexistente, dependendo do estado da federação a ser considerado.

O autor acrescenta que "talvez por ranços do passado, hoje seja necessário que se construam parâmetros para a atuação desse profissional numa perspectiva crítica e emancipatória." Observa, ainda, que existe uma real necessidade de atuação desses profissionais no contexto da educação escolar, tendo em vista, não somente sua atuação enquanto mediador entre o aluno, processos e contextos que o perpassam, mas, também, se 
comprometendo com a gestão do trabalho em equipes multidisciplinares, uma vez que "a razão de ser da escola e da própria educação é o aluno, centro dos estudos da orientação educacional" (PASCOAL, 2006, p. 115). Para ele, o trabalho do orientador junto aos demais profissionais da escola, é essencial para a organização e mobilização do processo educativo.

A partir das abordagens teóricas apresentadas, ressalta-se o valor do orientador educacional para o processo de ensino e de aprendizagem frente a tantas demandas, desafios e controvérsias que perpassam o contexto desafiador da escola contemporânea.

Nessa direção, foi pertinente ao contexto desta produção, a partilha de uma experiência escolar que ocorreu nas dependências de uma escola pública estadual, que atende alunos da segunda fase do Ensino Fundamental localizada em uma cidade de médio porte do sul do estado de Minas Gerais. A experiência foi idealizada, desenvolvida e relatada por uma orientadora educacional, com formação em pedagogia e atuante no cargo há cinco anos e compartilhada com um grupo de professores e gestores que participavam de um projeto extensionista desenvolvido por pesquisadores vinculados a um programa de pós-graduação em Educação. Os pesquisadores propuseram ao grupo o compartilhamento de narrativas orais e/ou escritas sobre suas experiências com alunos com deficiência. As atividades do projeto ocorreram ao final do período letivo de 2019.

Observados os princípios éticos, a orientadora educacional iniciou a partilha de sua experiência com um breve relato de suas percepções e vivências na função de gestora educacional, assumindo, oportunamente, o papel de mediar as relações que envolvem escolaaluno-família-comunidade-sociedade, com vistas a melhorar o processo de ensino e de aprendizagem escolar.

Iniciei minha trajetória como Orientadora Educacional nesta Escola (mencionou o nome da escola), no ano de 2016. Era a minha primeira experiência neste cargo, no entanto, o mesmo sempre me chamou atenção. Logo de início, percebi que a tarefa não seria nada fácil, haja vista a demanda que naquele momento me foi apresentada. Aos poucos, fui me familiarizando com os alunos, para além da escola. Pude sentiro currículo oculto que permeava as relações a cada dia, fator este imprescindivel para o trabalho que desenvolvia. Começaram então a surgir temáticas a serem trabalhadas em forma de projetos relacionados à diversidade, o que me levou a perceber que o "chão" da escola é lugar ideal para conscientização do respeito mútuo, um verdadeiro "canteiro para semear pessoas de bem” que um dia estarão colaborando para uma sociedade mais justa e fraterna. Minhas percepções a respeito do trabalho que venho desenvolvendo, são diversas, pois cada dia que se inicia vem acompanhado por uma novidade relacionada a um (a) novo (nova) aluno (a), uma situação diferente, com pessoas diferentes, ou seja, a responsabilidade é muito grande, considerando cada ser, cada história. Percebo que o fator "tempo", ou seja, a falta dele, pode contribuir para que olhemos depressa demais para esses meninos e meninas e que de repente este talvez seja o seu único "olhar"! (Excerto do relato de percepções e experiências da orientadora educacional no exercício de sua função na escola em que atua) 
O envolvimento da orientadora educacional com o projeto de extensão e as reflexões que fez mediante as narrativas que produziu nesse âmbito, contribuíram para que, no ano seguinte, ela tomasse as narrativas como instrumento para desenvolver o trabalho com as turmas de alunos que acompanhava, como é possível notar em seu relato:

[...] Após conhecer algumas concepções sobre narrativas, seu uso como instrumento escolar me pareceu pertinente e viável para a nossa escola, já que é intenção era de trabalhar de forma mais efetiva para favorecer o processo de ensino, de aprendizagem e a inclusão de todos os alunos, foco principal de nossa instituição para este periodo letivo. [...] (Excerto do diálogo entre a pesquisadora e a orientadora educacional)

A orientadora participou do referido projeto extensionista no qual pode, pelas narrativas, dar forma e sentido às suas experiências (PASSEGGI, 2010) e, desse modo, perceber a relevância da produção narrativa tanto para o conhecimento de si como para compreender o outro, pois quem narra, o faz para um interlocutor e, na compreensão de Freitas (2019), a narrativa como instrumento técnico-semiótico transforma tanto o narrador como seu interlocutor.

Assim, no início do ano letivo de 2020, a abertura de novas turmas do sexto ano do ensino fundamental e consequente demanda da orientadora educacional em conhecer os alunos dessas turmas, a mobilizaram para elaborar a estratégia de produção de narrativas com esses alunos, a fim de conhecer suas histórias de vida. A seguir, a orientadora relata como iniciou este trabalho:

[...] Apresentei-me então às duas turmas de alunos do sexto ano como Orientadora Educacional da escola. Expliquei a eles a minha função na escola, colocando-me à disposição de todos. Entreguei a eles uma folha e disse que para melhor realizar minha atividade na escola, gostaria que cada um escrevesse na folha sobre a sua vida. (Excerto do diálogo entre a pesquisadora e a orientadora educacional acerca da implementação da narrativa entre os alunos)

O perfil das turmas do sexto ano, as quais a orientadora se refere em sua narrativa, está apresentado no quadro 1:

Quadro 1 - Descrição das características das turmas e alunos envolvidos na experiência com narrativas.

\begin{tabular}{|c|c|c|}
\hline Turmas envolvidas & \multicolumn{2}{|c|}{$6^{\circ}$ ano 1 e $6^{\circ}$ ano 2} \\
\hline Idade dos alunos & \multicolumn{2}{|c|}{64 e 12 anos } \\
\hline Total de alunos nas duas turmas & 34 meninas & 30 meninos \\
\hline Sexo & \multicolumn{2}{|c|}{44} \\
\hline $\begin{array}{c}\text { Total dos alunos participantes da experiência } \\
\text { com narrativa proposta pela gestora }\end{array}$ & \\
\hline
\end{tabular}




\begin{tabular}{|c|c|c|}
\hline Sexo & 15 meninas & 29 meninos \\
\hline
\end{tabular}

Fonte: Elaborado pelo autoras.

Neste contexto, os relatos narrativos produzidos pelos alunos a partir da questão disparadora elaborada pela especialista, configuraram-se como a sua primeira experiência profissional com o propósito de eleger um instrumento mediador acessível ao contexto educacional que pudesse auxiliá-la no entendimento das histórias de vida dos alunos ingressantes.

Em seguida, a especialista educacional iniciou o relato de sua experiência com o uso de narrativa por alunos ingressantes do sexto ano do ensino fundamental, no intuito de conhecer a realidade, as necessidades e a singularidade desses alunos recém-chegados à comunidade escolar. Ela revela que:

Houve os que nada escreveram, outros que se recusaram a escrever e, ainda, aqueles que escreveram superficialmente. Sobre eles, acho que devemos ter um olhar mais atento no processo. Um olhar para além do que aparentam. (Excerto do diálogo entre a pesquisadora e a orientadora educacional acerca de sua análise do trabalho com narrativas que desenvolveu com os alunos)

Ao ler as narrativas dos alunos, a orientadora educacional constata que alguns escreveram superficialmente. Embora ela não explicite em seus dizeres o conteúdo dessa escrita, ela revela sua preocupação com esses alunos e a necessidade de acompanhá-los mais atentamente. Tal fato evidencia o papel da narrativa como instrumento que mobiliza reflexões e possibilita o conhecimento sobre o sujeito, indo assim, ao encontro das ideias de Frauendorf et al. (2016), que apontam a relevância da narrativa para o conhecimento do cotidiano escolar e de seus atores.

A utilização de narrativas escritas produzidas por alunos ingressantes no sexto ano do ensino fundamental da escola foi considerada pela orientadora educacional, um instrumento viável e de grande relevância em suas intervenções a favor do desenvolvimento do processo de ensino e de aprendizagem e da inclusão de alunos novatos na instituição.

O uso das narrativas direcionadas aos alunos novatos como instrumento mediador foi bem ao encontro das propostas de inclusão da escola: conhecermos os alunos em suas singularidades e talvez assim possamos achar melhores caminhos no sentido de minimizar os desvios no processo de ensino e aprendizagem na escola, favorecendo também a sua integração com os demais e com as famílias. [...] (Excerto do diálogo entre a pesquisadora e a orientadora educacional acerca de sua análise da atividade desenvolvida com os alunos)

No excerto acima, é possível perceber que a reflexão da orientadora educacional acerca do trabalho com narrativas vai ao encontro de estudos que apontam a potência da narrativa 
como instrumento que possibilita conhecer os sujeitos, seus modos de dizer, de sentir e de se colocarem no mundo (PASSEGGI, 2010; PASSEGGI, 2018).

Considerada, neste contexto, como uma importante forma de mediação, adequadas à observação, à compreensão, ao acompanhamento e ao desenvolvimento de crianças e jovens em suas questões educativas, o uso das escritas narrativas dos alunos foi importante para a articulação entre os sentidos e as relações que emergem da comunidade escolar envolvida com o aluno narrador.

As narrativas dos alunos revelaram suas condições de vida, particularidades, sonhos, angústias, frustrações, medos, etc. Assim, pude olhar para eles para além do que eles apresentam externamente, em suas falas e em seus comportamentos na escola. [...]

[...] desta forma, olhando para particularidades trazidas por cada aluno em suas narrativas pude refletir sobre novas maneiras de agir a favor do desenvolvimento do aluno na escola. (Excerto do diálogo entre a pesquisadora e a orientadora educacional acerca de sua análise da atividade desenvolvida com os alunos)

A orientadora pedagógica revela, como esses dizeres, seu entendimento acerca do desenvolvimento humano, ou seja, como as condições reais de vida, impactaram na constituição psíquica dos sujeitos e, a partir dessa compreensão, ela reflete sobre modos possíveis de estabelecer relações com os alunos, a fim de propiciar processos mais efetivos de ensinoaprendizagem.

Desta forma, em consonância com as proposições vygotskyanas a respeito da natureza histórica e social da constituição humana (VYGOTSKY, 1991), para a especialista, a singularidade humana origina-se nas relações sociais e o que os alunos revelam em suas narrativas diz respeito ao modo como elaboram suas vivências. Ademais, as narrativas escritas contribuíram para que ela pudesse refletir acerca dos sentidos que têm as suas ações no contexto escolar.

A orientadora educacional, durante o diálogo com a pesquisadora, compartilhou algumas narrativas produzidas pelos alunos, a fim de elucidar suas percepções sobre o trabalho desenvolvido.

[...] tenho muitas dificuldades com as matérias. Eu tenho vergonha de conversar com os amigos e tenho raiva quando alguém me insulta [...] (Excerto da narrativa escrita por um dos alunos)

[...] eu tenho dificuldades em meu dia a dia em casa, uma delas é cuidar das minhas irmãzinhas, uma de 4 meses e a outra de 1 ano e 7 meses [...] meu pai trabalha das 6 das manhã às 6 da tarde, aí fica difícil brincar, ir na casa dos amigos, jogar videogame etc. (Excerto da narrativa escrita por um dos alunos)

[...] Um dos meus defeitos é a tristeza, porque tem momentos que eu lembro de coisas tristes e, de repente, começo a chorar no meu travesseiro. Saindo do assunto, eu gosto da cor preta. Quase todos os dias eu me visto de preto, porque representa o que eu sinto. Hoje eu estou gótica. (Excerto da narrativa escrita por um dos alunos) 
A análise desses excertos narrativos produzidos por alguns alunos, revela como ao narrar, eles refletem sobre suas vivências, dando sentidos a elas. Dificuldade, vergonha, frustração, tristeza são emoções reveladas pelos alunos, que permitem conhecer um pouco de suas histórias de vida, seus modos de sentirem, de se relacionarem. Para Bruner (2002), a narrativa traduz uma forma singular dos sujeitos organizarem suas experiências humanas.

Desse modo, o trabalho desenvolvido pela especialista mediante o uso das narrativas como instrumento técnico-semiótico contribuiu para que ela elaborasse seus conhecimentos em relação aos alunos, assim como acerca de suas próprias demandas como educadora.

\section{Considerações Finais}

A motivação para a escrita deste texto decorre da necessidade de contribuir com estudos acerca da potência da narrativa como instrumento mediador de processos de elaboração de conhecimento.

À luz do referencial teórico histórico-cultural, a compreensão da narrativa como instância simbólica de linguagem permite destacar seu importante papel como atividade mediadora e, neste sentido, foi possível perceber que as narrativas dos alunos participantes incidiram nas reflexões da orientadora educacional sobre suas ações pedagógicas, com vistas a melhorar a qualidade do processo de escolarização no contexto desafiador da educação contemporânea, especialmente, em relação à diversidade de alunos inseridos na escola comum.

Nessa direção, as narrativas contribuíram para auxiliar o entendimento da especialista acerca da relação entre alunos, família e escola, e, a partir disso, viabilizar modos de comunicação mais efetivos entre escola-família.

As narrativas escritas por estudantes, enquanto instrumento técnico-semiótico, revelaram-se acessíveis às condições da escola, contribuindo de forma importante no aprimoramento do trabalho de orientação educacional e na inclusão escolar dos alunos matriculados no sexto ano do ensino fundamental desta escola.

Conhecer um pouco da vida e da realidade dos alunos nos oportunizou mais possibilidades para trabalhar com eles na orientação educacional, de fazer um pouco mais para orientá-los e apoiá-los na escola, além de subsidiar as orientações familiares. [...] (Excerto do diálogo entre a pesquisadora e a orientadora educacional)

Considerando os aspectos motivadores do uso das narrativas como estratégia de intervenção na orientação educacional, é pertinente destacar a importância a ser atribuída às pesquisas e às intervenções acadêmicas nas escolas de educação básica a fim de contribuir com o enfrentamento dos inúmeros desafios postos neste contexto. 
A promoção da partilha de conhecimentos e as reflexões entre universidade e escola, mencionados pela especialista em referência a sua participação em um projeto extensionista de caráter colaborativo, foram fundamentais para mobilizá-la a pensar em questões mediadoras do processo de ensino e de aprendizagem dos alunos, bem como contribuiu com as suas reflexões sobre novos caminhos para atender as demandas e superar os desafios vigentes.

Desta forma, oportunizar intervenções escolares orientadas por proposições da perspectiva histórico-cultural e de estudos narrativos configura-se como uma forma de vislumbrar novas possibilidades de práticas e intervenções pedagógicas neste contexto. Pode ser caracterizada ainda uma oportunidade de olhar para as questões da escola considerando os processos interativos e as condições concretas de vida humana que afetam as relações vividas na escola e as transformações dos alunos nesse ambiente.

O trabalho com narrativas no ambiente escolar contribui para que gestores educacionais e professores conheçam seus alunos, no que diz respeito as suas percepções acerca das experiências de vida (escolares, familiares etc.). Toma-se como hipótese para estudos futuros que tal conhecimento poderá tornar as relações de ensino mais significativas para todos. Ademais, ao narrar suas experiências, estudantes e educadores têm a oportunidade de refletir sobre elas e, a partir disso, atribuírem novos sentidos a essas experiências.

\section{Referências}

AGUIAR, Wanda Maria Junqueira; OZELLA, Sergio. Núcleos de significação como instrumento para a apreensão da constituição dos sentidos. Psicologia: ciência e profissão, Brasília, v. 26, n. 2, p. 222-245, Junho 2006. Disponível em:

http://www.scielo.br/scielo.php?script=sci_arttext\&pid=S141498932006000200006\&lng=en\&nrm=iso. Acesso em: 10 Nov. 2020. DOI: http://dx.doi.org/10.1590/S1414-98932006000200006.

BRUNER, Jerome. Realidade mental, mundos possíveis. Tradução de Marcos A. G. Domingues. Porto Alegre: Artmed, 2002.

DAINEZ, Débora; SMOLKA, Ana Luiza Bustamante. A função social da escola em discussão, sob a perspectiva da educação inclusiva. Educação e Pesquisa, São Paulo, v. 45, e187853, 2019. Disponível em: http://www.scielo.br/scielo.php?script=sci_arttext\&pid=S151797022019000100401\&lng=en\&nrm=iso $>$. Acesso: 1 Dez. 2020. DOI: https://doi.org/10.1590/s1678-4634201945187853.

FREITAS, Ana Paula de. A narrativa (auto)biográfica como meio/modo de elaboração de conhecimento de alunas de pedagogia no contexto da educação inclusiva. In: BERNARDES, Eliza Mattosinho (Org.). Narrativas e psicologia da educação: pesquisa e formação. São Paulo: Terracota, 2019. 
GONCALVES, Naiana Marinho et al. Narrativa e novas formas de cuidado em saúde mental. Caderno Brasileiro de Saúde Mental. Florianópolis, v. 8, n. 20, p. 157-180, 2016 Disponível em: http://pepsic.bvsalud.org/scielo.php?script=sci_arttext\&pid=S1984-

$21472016000300010 \& \operatorname{lng}=$ pt\&nrm=iso. Acesso em 29 Abr. 2020.

HANKE, Michael. Narrativas orais: formas e funções. Revista Contracampo, Rio de Janeiro, n. 9, 2003. Disponível em: https://periodicos.uff.br/contracampo/article/view/17361, Acesso em 15 Nov. 2020. DOI: https://doi.org/10.22409/contracampo.v0i09.490.

LURIA, Alexander Romanovich. Vigotski. In: VIGOTSKII, Lev Semenovich; LURIA, Alexander Romanovich; LEONTIEV, Alexis. Nikolaevich. Linguagem, desenvolvimento e aprendizagem. Tradução: Maria da pena Villalobos. 16 ed. São Paulo: Icone, 2018.

MARTINS, Lígia Márcia. Dialética singular-particular-universal: implicações do método materialista dialético para a psicologia e educação. In: FRANCO, Adriana de Fátima, TULESKI, Silvana Calvo, MENDONÇA, Fernando Wolff. Ser ou não ser na sociedade capitalista: o materialismo histórico-dialético como método da psicologia histórico-cultural e da teoria da determinação social dos processos de saúde e doença. Goiânia, Go: Phillos, 2020. Phillos, 2020. ISBN: 978-65-87324-14-2. Disponível em: http://www.editoraphillos.com. Acesso em: 15 Nov. 2020.

MARTINS, Lígia Márcia. O desenvolvimento do psiquismo e a educação escolar: contribuições à luz da psicologia histórico cultural e da pedagogia histórico-crítica. 1 ed. Campinas, São Paulo: Editora Autores Associados, 2013. 336 p.

MASCIA, M. A. A.; KONTOPODIS, M. Reflexão, educação e mudança da sociedade através de narrativas de alunas jovens de grupos minoritários: um diálogo entre Vigotski e Foucault. Zetetike, Campinas, SP, v. 18, 2011. DOI: 10.20396/zet.v18i0.8646674. Disponível em: https://periodicos.sbu.unicamp.br/ojs/index.php/zetetike/article/view/8646674. Acesso em: 1 dez. 2020.

PINO, Angel. Semiótica e cognição na perspectiva histórico-cultural. Temas em Psicologia. Ribeirão Preto, v. 3, n. 2, p. 31-40, ago. 1995. Disponível em: http://pepsic.bvsalud.org/scielo.php?script=sci_arttext\&pid=S1413389X1995000200005\&lng=pt\&nrm=iso $>$. acessos em 12 abril 2020.

TEIXEIRA, Leny Rodrigues Martins. As narrativas de professores sobre a escola e a mediação de um Grupo de Pesquisa-Formação. Revista Brasileira sobre Formação Docente, Belo Horizonte, v. 02, n. 03, p. 121-135, ago./dez. 2010. Disponível em: http://formacaodocente.autenticaeditora.com.br. Acesso em: 1 Dez. 2020.

VYGOTSKY, Lev. Semyonovich. A formação social da mente. São Paulo, SP: Martins Fontes, 1991.

CONNELLY, F. Michael; CLANDININ, D. Jean. Relatos de Experiencia e Investigación Narrativa. In: LARROSA, Jorge et. al. Déjame que te cuente: ensayos sobre narrativa y educación. Barcelona: Laertes, 1995, p. 11-59.

FRAUENDORF, Renata Barroso de Siqueira et al. Mais além de uma história: a narrativa como possibilidade de autoformação. Revista de Educação PUC-Campinas, [S.1.], v. 21, n. 3, p. 351-361, dez. 2016. ISSN 2318-0870. Disponível em: http://periodicos.puccampinas.edu.br/seer/index.php/reveducacao/article/view/2908. Acesso em: 30 set. 2020. DOI: https://doi.org/10.24220/2318-0870v21n3a2908.

PASSEGGI, Maria da Conceição. Contos da experiência, reflexividade e conhecimentos: uma combinatória de lógicas narrativas. In: NACARATO, Adair Mendes (org.). Pesquisa 
(com)narrativas: a produção de sentidos para experiências discentes e docentes. São Paulo: Editora Livraria da Física, 2018.

PASSEGGI, Maria da Conceição. Narrar é humano! Autobiografar é um processo civilizatório. In: PASSEGGI, Maria da Conceição; SILVA, Vivian Batista da (org.). Invenções de vidas, compreensão de itinerários e alternativas de formação. São Paulo: Cultura Acadêmica, 2010.

PASCOAL, M. O ORIENTADOR EDUCACIONAL NO BRASIL: UMA DISCUSSÃO CRÍTICA. Poíesis Pedagógica, v. 3, n. 3 e 4, p. 114-125, 25 out. 2006. Disponível em: https://www.revistas.ufg.br/poiesis/article/view/10549. Acesso em: 30 Set. 20. DOI: https://doi.org/10.5216/rpp.v3i3e4.10549.

PASCOAL, Miriam; HONORATO, Eliane Costa; ALBUQUERQUE, Fabiana Aparecida de. O orientador educacional no Brasil. Educação em Revista, Belo Horizonte, n. 47, p. 101-120, Junho 2008. Disponível em: http://www.scielo.br/scielo.php?script=sci_arttext\&pid=S010246982008000100006\&lng=en\&nrm=iso. Acesso em: 23 Jun. 20. DOI: https://doi.org/10.1590/S0102-46982008000100006.

SANTOS, Caio César Portella; SANT’ANA, Izabella Mendes. Educação, medicalização e desenvolvimento humano: uma leitura a partir da teoria histórico-cultural. Crítica Educativa, Sorocaba-SP, v. 2, n. 2, p. 248-264, jul./dez.2016. Disponível em:

https://www.criticaeducativa.ufscar.br/index.php/criticaeducativa/article/view/83. Acesso em: 30 Set. 20. DOI: https://doi.org/10.22476/revcted.v2i2.83.

SIRGADO, Angel Pino. O social e o cultural na obra de Vigotski. Educação \& Sociedade, Campinas, v. 21, n. 71, pág. 45-78, julho de 2000. Disponível em: http://www.scielo.br/scielo.php?script $=$ sci arttext\&pid $=\mathrm{S} 0101$ 73302000000200003\&lng=en\&nrm=iso. Acesso em: 1 Dez. 20. DOI: http://dx.doi.org/10.1590/S0101-73302000000200003

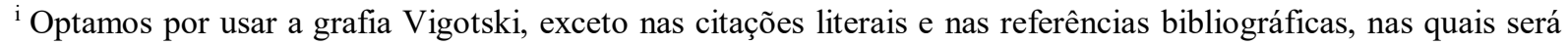
mantida a grafia original.
} 